\title{
Identification, characterization, and utilization of genome-wide simple sequence repeats to identify a QTL for acidity in apple
}

Qiong Zhang ${ }^{1,2 \dagger}$, Baiquan Ma ${ }^{1,2+}$, Hui Li ${ }^{3}$, Yuansheng Chang ${ }^{3}$, Yuanyuan $\mathrm{Han}^{3}$, Jing Li ${ }^{1}$, Guochao Wei ${ }^{1,2}$, Shuang Zhao ${ }^{1,2}$, Muhammad Awais Khan ${ }^{4}$, Ying Zhou', Chao Gu', Xingzhong Zhang ${ }^{3}$, Zhenhai Han ${ }^{3}$, Schuyler S Korban ${ }^{4}$, Shaohua Li ${ }^{1}$ and Yuepeng $\operatorname{Han}^{1 *}$

\begin{abstract}
Background: Apple is an economically important fruit crop worldwide. Developing a genetic linkage map is a critical step towards mapping and cloning of genes responsible for important horticultural traits in apple. To facilitate linkage map construction, we surveyed and characterized the distribution and frequency of perfect microsatellites in assembled contig sequences of the apple genome.
\end{abstract}

Results: A total of 28,538 SSRs have been identified in the apple genome, with an overall density of 40.8 SSRs per Mb. Di-nucleotide repeats are the most frequent microsatellites in the apple genome, accounting for $71.9 \%$ of all microsatellites. AT/TA repeats are the most frequent in genomic regions, accounting for $38.3 \%$ of all the G-SSRs, while AG/GA dimers prevail in transcribed sequences, and account for $59.4 \%$ of all EST-SSRs. A total set of 310 SSRs is selected to amplify eight apple genotypes. Of these, 245 (79.0\%) are found to be polymorphic among cultivars and wild species tested. AG/GA motifs in genomic regions have detected more alleles and higher PIC values than AT/TA or AC/CA motifs. Moreover, AG/GA repeats are more variable than any other dimers in apple, and should be preferentially selected for studies, such as genetic diversity and linkage map construction. A total of 54 newly developed apple SSRs have been genetically mapped. Interestingly, clustering of markers with distorted segregation is observed on linkage groups 1,2,10,15, and 16. A QTL responsible for malic acid content of apple fruits is detected on linkage group 8 , and accounts for $\sim 13.5 \%$ of the observed phenotypic variation.

Conclusions: This study demonstrates that di-nucleotide repeats are prevalent in the apple genome and that AT/ TA and AG/GA repeats are the most frequent in genomic and transcribed sequences of apple, respectively. All SSR motifs identified in this study as well as those newly mapped SSRs will serve as valuable resources for pursuing apple genetic studies, aiding the apple breeding community in marker-assisted breeding, and for performing comparative genomic studies in Rosaceae.

\section{Background}

The domesticated apple (Malus $\mathrm{x}$ domestica Borkh.) is one of the most economically important tree fruit crops worldwide. The apple is self-incompatible, highly heterozygous, and displays a juvenile period of 6 to 10 years or more. These characteristics render apple breeding

\footnotetext{
* Correspondence: yphan@wbgcas.cn

${ }^{\dagger}$ Equal contributors

'Key Laboratory of Plant Germplasm Enhancement and Specialty Agriculture, Wuhan Botanical Garden, the Chinese Academy of Sciences, Wuhan 430074, People's Republic of China

Full list of author information is available at the end of the article
}

programs difficult and time-consuming. To save time and land-space, as well as reduce cost of apple breeding programs, it is imperative to identify young seedlings with desirable traits early and accurately using molecular marker-assisted selection. Hence, identifying molecular markers linked to major genes/quantitative trait loci (QTL) contributing to desirable economic traits is an important goal in apple genetic studies. Several studies have identified QTLs contributing to important horticultural traits, such as resistance to fire blight and to woolly apple aphid [1-4], tree architecture [5,6], and fruit quality components [7].

\section{Biomed Central}


The cultivated apple is a diploidized autopolyploid species with 17 haploid chromosomes [8]. In recent years, apple genomic resources have greatly expanded, including a large expression sequence tag (EST) database $[9,10]$, a BAC-based genome-wide physical map [11], and a draft sequence of the apple genome [8]. Despite availability of the apple genome sequence, genetic linkage maps remain critical for identification of genomic regions associated with horticultural traits. In apple, several genetic linkage maps have been reported. For example, Maliepaard et al. [12] have developed the first apple linkage map using mostly restriction fragment length polymorphisms (RFLP) and amplified fragment length polymorphism (AFLP) markers. Later, microsatellites or simple sequence repeats (SSRs) have been widely exploited and used to construct high-density linkage maps for apple [13-17]. SSRs, either genomic SSRs (gSSRs) or expressed sequence tag (EST) SSRs (ESTSSRs), are co-dominant, reliable, and highly reproducible. To date, more than 300 gSSRs have been developed and mapped in apple [13-15,17]. More recently, SSRs associated with expressed sequences have also been extensively exploited, and a total of 323 EST-SSRs have been developed and mapped in apple [18]. Despite this progress, the number of SSRs publicly available for apple is not sufficient for the development of high-resolution linkage maps or for rapid saturation of specific map regions, both of which are essential for QTL finemapping and positional gene cloning.

Construction of a genetic map requires analysis of hundreds of markers over a relatively large number of plants. Thus, genotyping analysis is a labor-intensive and time-consuming undertaking. During the past several years, rapid progress has been made in developing molecular tools to enable large-scale segregation analysis in genetic studies. PCR-based markers adapted to largescale genotyping systems can be designed for constructing genetic linkage maps. SSRs are amenable for analysis using automated DNA sequencers, and thus can be adapted for high-throughput genotyping. For example, fluorescent microsatellite genotyping has been successfully carried out recently to develop a high-density linkage map for apple within a few months [18].

In addition to their usefulness in constructing linkage mapping, SSRs are useful for population genetic studies as well as for comparative genomics efforts [19]. Genomewide analysis of SSRs is not only an efficient strategy to develop abundant molecular markers, but may also provide insights into possible roles of SSRs in chromosome structure, function, and evolution [20]. Therefore, it is important to continue to develop SSR markers for further progress of genetics and genomics efforts for apple. To date, there are a few reports on genome-wide characterization of microsatellite sequences in the apple genome $[13,14]$. Recently, the apple genome has been sequenced (database is available at http://www.rosaceae.org/projects/apple_genome), thus providing an opportunity to identify and develop robust genome-wide SSRs. In this study, distribution and variation of size of microsatellites within the DNA sequence of the apple genome have been characterized. The aim of this study is to develop SSRs for constructing genetic linkage maps to identify QTLs for fruit acidity. Our results will aid in conducting apple genetic studies, pursuing efficient apple breeding, and performing comparative genomic studies in rosaceae.

\section{Results}

\section{Simple sequence repeats in the apple genome}

The distribution of microsatellites of minimum lengths of $20 \mathrm{bp}$ in assembled contig sequences of the apple genome was analyzed [8]. A total of 28,538 microsatellites, consisting of a variety of repeat types, were identified (Table 1). Di-nucleotide repeats were the most abundant, accounting for $71.9 \%$ of all SSRs. Tri-, tetra-, penta-, and hexa-nucleotide repeats accounted for 12.3\%, 6.3\%, 0.9\%, and $0.2 \%$, respectively, of all SSRs. Of the di-nucleotide repeats, AT/TA was the most abundant, accounting for $32.8 \%$ of all di-nucleotide repeats, while AG/GA and AC/CA repeats accounted for $30.7 \%$ and $8.5 \%$, respectively. It is worth noting that SSR motifs represented variants of both strands of the DNA sequence. GC/CG repeats were rather rare, and only a single CG repeat was found. Among tri-nucleotide repeats, AAC/ACA/ CAA was the most abundant, accounting for $39.8 \%$ of all tri-nucleotide repeats, followed by AAT/ATA/ TAA (22.0\%) and AAG/AGA/GAA (22.0\%). Of tetranucleotide repeats, AAAT/TAAA/ATAA/AATA was the most abundant, accounting for $35.8 \%$ of all tetranucleotide repeats, and followed by TACA/ACAT/ CATA/ATAC (28.1\%). Among penta- and hexanucleotide repeats, AT-rich repeats were the most abundant, accounting for $24.5 \%$ and $11.6 \%$ of all penta- and hexa-nucleotide repeats, respectively. Moreover, 63.5\%, $88.4 \%, 91.5 \%, 98.5 \%$, and $93.4 \%$ of di-, tri-, tetra-, penta-, and hexa-nucleotide repeats, respectively, were less than $30 \mathrm{bp}$ in length. A small number of di-nucleotide repeats (15.0\%) were longer than $50 \mathrm{bp}$ in length, whereas few tri-, tetra-, pentra-, or hexa-nucleotide repeats $(<5 \%)$ were longer than $40 \mathrm{bp}$ in length. Briefly, AT/TA and AG/GA di-nucleotide repeats were the most abundant SSRs in the apple genome, and most SSR motifs were shorter than 30 bp in length.

To investigate the distribution of SSRs in coding DNA sequences (CDSs), untranslated regions (UTRs), and genomic regions of the apple genome, DNA sequences flanking SSR motifs were compared with both the apple CDS database (http://www.rosaceae.org/projects/apple_genome) and expression sequence tag (EST) database of NCBI. Of 
Table 1 Composition and length distribution of major SSR types in the apple genome

\begin{tabular}{|c|c|c|c|c|c|c|c|}
\hline \multirow[t]{2}{*}{ Repeat unit } & \multirow[t]{2}{*}{ Repeat type } & \multicolumn{4}{|c|}{ Repeat length (bp) } & \multirow[t]{2}{*}{ Total } & \multirow{2}{*}{$\begin{array}{c}\text { Frequency } \\
\text { (\%) }\end{array}$} \\
\hline & & $<30$ & $30-40$ & $40-50$ & $>50$ & & \\
\hline \multirow[t]{5}{*}{ Dimer } & $\mathrm{AC} / \mathrm{CA}$ & 1883 & 357 & 106 & 73 & 2419 & 8.48 \\
\hline & $\mathrm{AG} / \mathrm{GA}$ & 5115 & 2090 & 953 & 595 & 8753 & 30.67 \\
\hline & AT/TA & 6035 & 1968 & 854 & 495 & 9352 & 32.77 \\
\hline & CG & 1 & 0 & 0 & 0 & 1 & 0.00 \\
\hline & Total & 13033 & 4415 & 1913 & 1163 & 20524 & 71.92 \\
\hline \multirow[t]{5}{*}{ Trimer } & AAT/ATA/TAA & 591 & 97 & 41 & 44 & 773 & 2.71 \\
\hline & $\mathrm{AAC} / \mathrm{ACA} / \mathrm{CAA}$ & 1342 & 44 & 7 & 3 & 1396 & 4.89 \\
\hline & AAG/AGA/GAA & 643 & 66 & 20 & 44 & 773 & 2.71 \\
\hline & Others & 520 & 31 & 4 & 6 & 561 & 1.97 \\
\hline & Total & 3096 & 238 & 72 & 97 & 3503 & 12.27 \\
\hline \multirow[t]{8}{*}{ Tetramer } & AAAT/TAAA/ATAA/AATA & 631 & 10 & 0 & 1 & 642 & 2.25 \\
\hline & AATT/ATTA/TTAA/TAAT & 93 & 0 & 0 & 0 & 93 & 0.33 \\
\hline & AAAG/AAGA/AGAA/GAAA & 109 & 10 & 2 & 2 & 123 & 0.43 \\
\hline & TACA/ACAT/CATA/ATAC & 404 & 76 & 15 & 8 & 503 & 1.76 \\
\hline & GTT/TGTT/TTGT/TTG & 90 & 1 & 1 & 0 & 92 & 0.32 \\
\hline & AGGG/GAGG/GGAG/GGGA & 91 & 4 & 0 & 0 & 95 & 0.33 \\
\hline & Others & 222 & 17 & 5 & 1 & 245 & 0.86 \\
\hline & Total & 1640 & 118 & 23 & 12 & 1793 & 6.28 \\
\hline \multirow[t]{8}{*}{ Pentamer } & AAAAT/AAATA/AATAA/ATAAATTAAAA & 494 & 2 & 0 & 0 & 496 & 1.74 \\
\hline & GTTT/TGTT/TTGTT/TTTGT/TTTTG & 154 & 1 & 0 & 0 & 155 & 0.54 \\
\hline & AATTT/ATTTA/TTTAA/TTAAT/TAATT & 94 & 1 & 0 & 0 & 95 & 0.33 \\
\hline & AAAAG/AAAGA/AAGAA/AGAAA/GAAAA & 115 & 0 & 0 & 0 & 115 & 0.40 \\
\hline & AAGCC/AGCCA/GCCAA/CCAAG/CAAGC & 170 & 0 & 0 & 0 & 170 & 0.60 \\
\hline & CCCTG/CCTGC/CTGCC/TGCCC/GCCCT & 121 & 7 & 0 & 1 & 129 & 0.45 \\
\hline & Others & 747 & 15 & 1 & 1 & 764 & 2.68 \\
\hline & Total & 1895 & 26 & 1 & 2 & 1924 & 6.74 \\
\hline \multirow[t]{9}{*}{ Hexamer } & AAAAAT/AAAATA/AAATAA/AATAAA/ATAAAA/TAAAAA & 106 & 2 & 2 & 0 & 110 & 0.39 \\
\hline & AAAAAG/AAAAGA/AAAGAA/AAGAAA/AGAAAA/GAAAAA & 38 & 1 & 0 & 0 & 39 & 0.14 \\
\hline & AAAAAC/AAAACA/AAACAA/AACAAA/ACAAAA/CAAAAA & 34 & 0 & 0 & 0 & 34 & 0.12 \\
\hline & СССТСТ/ССТСТС/СТСТСС/ТСТССС/СТСССТ/ТСССТС & 33 & 2 & 2 & 0 & 37 & 0.13 \\
\hline & ATACAT/TACATA/ACATAT/CATATA/ATATAC/TATACA & 40 & 6 & 0 & 1 & 47 & 0.16 \\
\hline & AGAGTG/GAGTGA/AGTGAG/GTGAGA/TGAGAG/GAGAGT & 21 & 1 & 0 & 0 & 22 & 0.08 \\
\hline & ССТCTC/СТCTCC/TCTCCC/СТCCСТ/TCCСТC/СCСТCT & 35 & 3 & 1 & 0 & 39 & 0.14 \\
\hline & Others & 434 & 23 & 7 & 1 & 465 & 1.63 \\
\hline & Total & 741 & 38 & 12 & 2 & 793 & 2.78 \\
\hline
\end{tabular}

SSRs with at least 20 bp in length and more than 3 repeats were recorded. SSR motifs represent variants of both strands of the DNA sequence (e.g., AC/CA includes the reverse complements GT and TG).

28,538 SSRs in scaffold sequences of the apple genome, 513 (1.8\%), 4,120 (14.4\%), and 23,905 (83.8\%) were present in CDSs, UTRs, and genomic DNA, respectively (Table 2). Of CDS-SSRs, tri-nucleotide repeats were the most abundant, accounting for $51.7 \%$ of all CDS-SSRs, and followed by hexa-nucleotide repeats (28.5\%). In contrast, among UTR-
SSRs or gSSRs, di-nucleotide repeats were the most abundant, accounting for $73.0 \%$ and $72.9 \%$ of all UTR-SSRs and gSSRs, respectively. AG/GA dimers prevailed in transcribed sequences and accounted for $66.8 \%$ of all UTR-SSRs. Of all gSSRs, AT/TA and AG/GA dimers accounted for 38.3\% and $24.8 \%$, respectively. Briefly, AT/TA and AG/GA were 
Table 2 Distribution of SSR types in coding DNA sequences (CDSs), untranslated regions (UTRs), and genomic DNA of the apple genome

\begin{tabular}{|c|c|c|c|c|c|c|c|}
\hline \multirow[t]{2}{*}{ Repeat } & \multirow[t]{2}{*}{ Region } & \multicolumn{4}{|c|}{ Repeat length (bp) } & \multirow[t]{2}{*}{ Total } & \multirow{2}{*}{$\begin{array}{c}\text { Frequency } \\
\text { (\%) }\end{array}$} \\
\hline & & $<30$ & $30-40$ & $40-50$ & $>50$ & & \\
\hline \multirow[t]{3}{*}{ Dimer } & CDS & 76 & 0 & 0 & 0 & 76 & 0.27 \\
\hline & UTR & 2098 & 598 & 158 & 153 & 3007 & 10.54 \\
\hline & Genomic & 10860 & 3817 & 1755 & 1010 & 17442 & 61.12 \\
\hline \multirow[t]{3}{*}{ Trimer } & CDS & 260 & 5 & 0 & 0 & 265 & 0.93 \\
\hline & UTR & 425 & 22 & 3 & 2 & 452 & 1.58 \\
\hline & Genomic & 2411 & 211 & 69 & 95 & 2786 & 9.76 \\
\hline \multirow[t]{3}{*}{ Tetramer } & CDS & 10 & 0 & 0 & 0 & 10 & 0.04 \\
\hline & UTR & 158 & 11 & 1 & 1 & 171 & 0.60 \\
\hline & Genomic & 1472 & 107 & 22 & 11 & 1612 & 5.65 \\
\hline \multirow[t]{3}{*}{ Pentamer } & CDS & 16 & 0 & 0 & 0 & 16 & 0.06 \\
\hline & UTR & 223 & 7 & 0 & 0 & 230 & 0.81 \\
\hline & Genomic & 1658 & 19 & 1 & 2 & 1680 & 5.89 \\
\hline \multirow[t]{3}{*}{ Hexamer } & CDS & 136 & 8 & 1 & 1 & 146 & 0.51 \\
\hline & UTR & 248 & 10 & 2 & 0 & 260 & 0.91 \\
\hline & Genomic & 355 & 20 & 9 & 1 & 385 & 1.35 \\
\hline
\end{tabular}

the most abundant in genomic DNA and transcribed sequences of the apple genome, respectively (Figure 1).

\section{SSR polymorphisms in apple cultivars and wild species} As demonstrated above, most SSR motifs in the apple genome were either di- or tri- nucleotide repeats. Thus, 310 primer pairs flanking 278 di-nucleotides repeats and 32 tri-nucleotide repeats were designed to test polymorphism among eight apple genotypes, including four cultivars and four wild species (Table 3). Of 310 primer pairs, 298 (96.1\%) were amplified, and 245 (79.0\%) showed polymorphic banding patterns in all genotypes tested. The average numbers of alleles amplified by gSSRs, UTR-SSRs, and CDS-SSRs were 3.5, 2.4, and 2.6, respectively. The average number of alleles amplified by each SSR was 3.2 for the four apple cultivars and 3.4 for the four wild apple species; moreover, each dimer or trimer detected 3.4 and 2.5 alleles, respectively, in these two sets of genotypes. The average PIC values for gSSRs, UTR-SSRs, and CDS-SSRs were 0.64, 0.48, and 0.54, respectively, for all genotypes tested. The average PIC value for all SSR loci was 0.57 for four apple cultivars, and with a higher average PIC value of 0.66 for the four wild apple species. On average, gSSRs flanking AC/CA, AG/GA, and AT/TA motifs had 2.8, 3.5, and 3.2 alleles in all eight genotypes, respectively. The average PIC values of AC/CA, AG/GA, and AT/TA motifs in genomic regions were $0.52,0.67$, and 0.63 , respectively, over all eight genotypes.
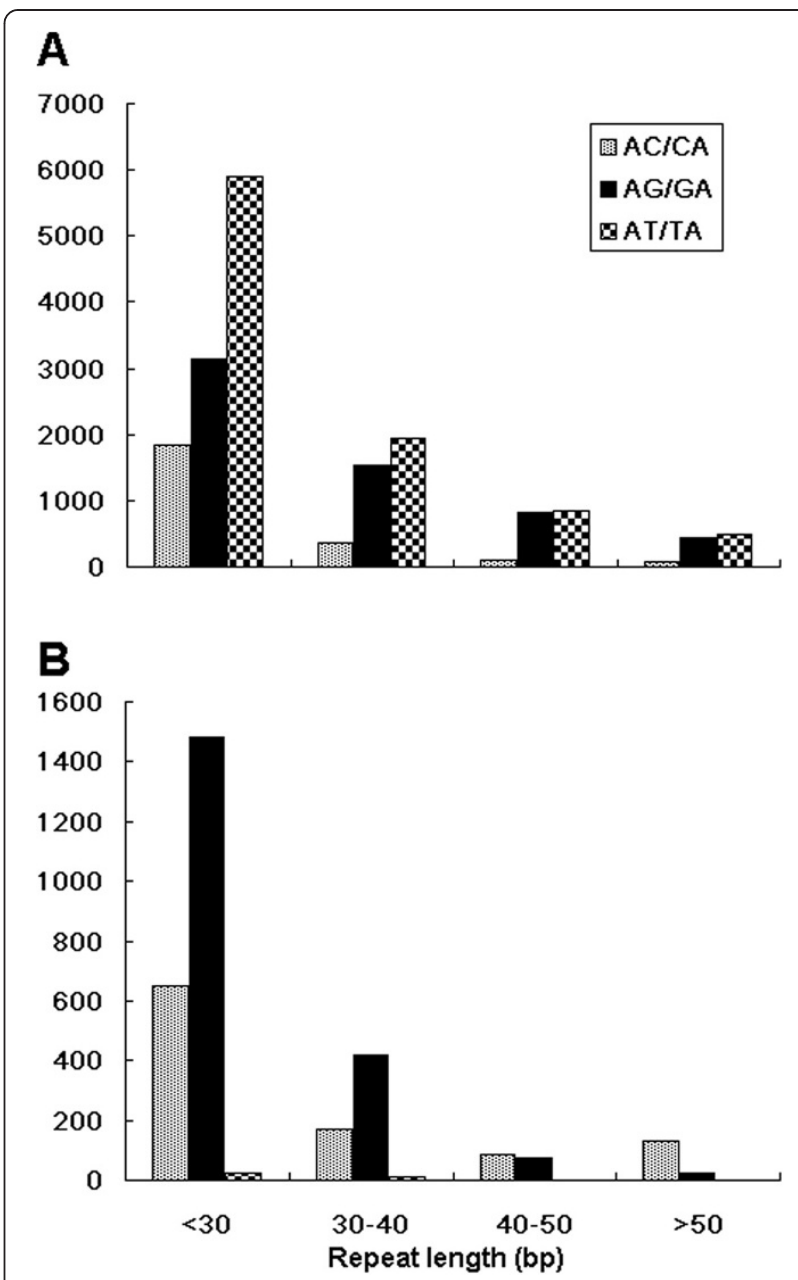

Figure 1 Distribution of dimeric SSRs in genomic DNA (A) and transcribed sequences (B) of the apple genome

Among all 310 primer pairs, 81 primer pairs were identified to be polymorphic between 'Golden Delicious' and 'Jonathan', parents of the $F_{1}$ mapping population. Thus, these primer pairs were used to construct a genetic linkage map for apple, and these were designated with a 'WBGCAS' prefix to distinguish them from previously published SSRs. Primer sequences of these newly identified SSRs are listed in Additional file 1.

\section{Construction of a genetic linkage map of apple}

A total of 676 previously published SSR markers were initially used to screen the parents 'Golden Delicious' and 'Jonathan'. Of 676 SSR markers, 327 were selected from a public domain of apple molecular markers (http://www.hidras.unimi.it/) and 349 were recently developed EST-SSRs and BAC-end sequence (BES)-SSRs [18,21]. As a result, 218 SSRs (98 gSSRs, 15 BES-SSRs, and 105 EST-SSRs) were identified to be polymorphic between 'Golden Delicious' and 'Jonathan'. These polymorphic SSRs, together with the newly-developed SSRs 
Table 3 Average allele numbers and PIC values of SSRs in eight apple genotypes

\begin{tabular}{|c|c|c|c|c|c|c|c|c|}
\hline \multirow[t]{2}{*}{ SSR region } & \multirow[t]{2}{*}{ Type } & \multirow[t]{2}{*}{ No. of SSRs } & \multicolumn{3}{|c|}{ Average allele number } & \multicolumn{3}{|c|}{ Average PIC value } \\
\hline & & & $\mathrm{C}^{*}$ & $\mathbf{W}^{*}$ & $\mathrm{C}+\mathrm{W}^{*}$ & $\mathrm{C}^{*}$ & $\mathbf{W}^{*}$ & $\mathrm{C}+\mathrm{W}^{*}$ \\
\hline \multirow[t]{2}{*}{ CDS } & Dimer & 3 & 2.50 & 2.75 & 2.63 & 0.44 & 0.48 & 0.46 \\
\hline & Trimer & 9 & 2.53 & 2.71 & 2.62 & 0.55 & 0.59 & 0.57 \\
\hline \multirow[t]{2}{*}{ UTR } & Dimer & 28 & 2.26 & 2.56 & 2.41 & 0.49 & 0.51 & 0.50 \\
\hline & Trimer & 11 & 2.27 & 2.27 & 2.27 & 0.41 & 0.45 & 0.43 \\
\hline \multirow[t]{6}{*}{ Genomic } & Dimer & & & & & & & \\
\hline & $\mathrm{AC} / \mathrm{CA} / \mathrm{TG} / \mathrm{GT}$ & 17 & 2.40 & 3.20 & 2.80 & 0.44 & 0.60 & 0.52 \\
\hline & $\mathrm{AG} / \mathrm{GA} / \mathrm{TC} / \mathrm{CT}$ & 102 & 3.20 & 3.69 & 3.45 & 0.62 & 0.73 & 0.67 \\
\hline & AT/TA & 63 & 2.75 & 3.19 & 2.97 & 0.56 & 0.69 & 0.63 \\
\hline & Total & 182 & 3.51 & 3.67 & 3.59 & 0.60 & 0.71 & 0.65 \\
\hline & Trimer & 12 & 2.57 & 2.57 & 2.57 & 0.52 & 0.56 & 0.54 \\
\hline
\end{tabular}

C: Four apple cultivars, including 'Golden Delicious', 'Jonathan', 'Luao', and 'Starkrimson'. W: Four wild apple species, including M. prunifolia (Willd.) Borkh. ('Regunzihaitang'), M. sieversii (Lebed.) Roem. ('Xinjiangyepingguo 12'), M. × robusta Rehd. ('Pingding Crab'), and M. asiatica Nakai ('Naizi'). C+W: Both four apple cultivars and four wild apple species.

with a 'WBGCAS' prefix designation, as described above, were then used to screen all seedlings of the mapping population of 'Jonathan' $\mathrm{x}$ 'Golden Delicious'. This revealed presence of five segregation types, as defined in JoinMap 4.0, including lm $\times l l, n n \times n p, h k \times h k$, ab $\times c d$, and ef $\times$ eg (Additional file 2). Of 299 tested SSRs, 12 amplified two loci. As a result, a total of 311 loci were scored. Subsequently, 50 loci were excluded from linkage analysis as they either failed to link with any of the linkage groups or their distorted segregation conflicted with segregation patterns of neighboring markers. Moreover, 44 seedlings were found to carry several double recombination events, and were excluded from further linkage analysis. Finally, a consensus linkage map consisting of 251 loci $(91 \mathrm{l} \mathrm{m} \times \mathrm{ll}, 95 \mathrm{nn} \times \mathrm{np}, 15 \mathrm{hk} \times \mathrm{hk}, 15 \mathrm{ab} \times \mathrm{cd}$, and 50 ef $\times$ eg) along 21 linkage groups was successfully generated (Figure 2). These 21 linkage groups were assigned to their respective chromosomes, based on previously published linkage maps [12-18]. Each linkage group had 8 to 24 markers with an average of 14.7. The consensus linkage map spanned $1720.9 \mathrm{cM}$ with an average density of $6.8 \mathrm{cM}$ per marker.

Of 251 SSR loci along the consensus map, 141 and 148 were mapped onto linkage maps of 'Jonathan' and 'Golden Delicious', respectively. The total lengths of linkage maps of 'Jonathan' and 'Golden Delicious' were 1228.4 and $1403.9 \mathrm{cM}$, respectively, and the average densities were 8.7 and 9.4 cM per SSR, respectively.

\section{Identification of QTLs responsible for malic acid content in ripe apple fruit}

Of 242 F1 seedlings used to construct the linkage map, 162 were reproductive and bore fruits. Collected fruits from these seedlings were evaluated for malic acid contents. The average content of malic acid for this segment of the mapping population was $2.42 \mathrm{mg} / \mathrm{g}$, ranging from 0.44 to 6.58 . Interval mapping was conducted for malic acid content, and a QTL for malic acid content was detected on linkage group 8 of 'Jonathan', and this was flanked by markers $\mathrm{CH} 04 \mathrm{~g} 12$ and Hi20b03. The QTL explained $\sim 13.5 \%$ of the phenotypic variation, with an LOD score of 3.4. In the Kruskal-Wallis analysis, the $M a$ QTL was supported with a highly significant $(\mathrm{P}<0.0001)$ value of the $K$ statistic, 15.9 for malic acid content.

\section{Discussion}

\section{Frequency and variation of SSRs identified in the apple genome}

Currently, there is no consensus on the definition of SSRs, particularly regarding the minimum length of repeat sequences [22]. In this study, the distribution and frequency of SSRs has been analyzed, with repeat unit lengths of 2 to $6 \mathrm{bp}$ and a minimum length of $20 \mathrm{bp}$ in assembled contigs of the DNA sequence of the apple genome. A total of 28,538 SSRs were identified in the apple genome (Additional file 3). Given the estimated $700 \mathrm{Mb}$ size of the apple genome [8], the SSR density is $\sim 40.8$ per $\mathrm{Mb}$ in the DNA sequence of apple. This observed SSR frequency in the apple genome is lower than those reported for other plant species. For example, overall densities of SSRs in genomes of Arabidopsis, rice, and cucumber are 874, 807, and 551 SSRs/Mb, respectively $[23,24]$. This is probably mainly due to the fact that higher stringent conditions have been used in defining SSRs in this study than those used previously for Arabidopsis, rice, and cucumber. For Arabidopsis, rice, and cucumber, di- and tri-nucleotide repeats of minimum lengths of 12 di-nucleotide repeats have been recorded, along with tetra- to hexa-nucleotide repeats of at least three repeat units [24]. Moreover, it is worth mentioning 


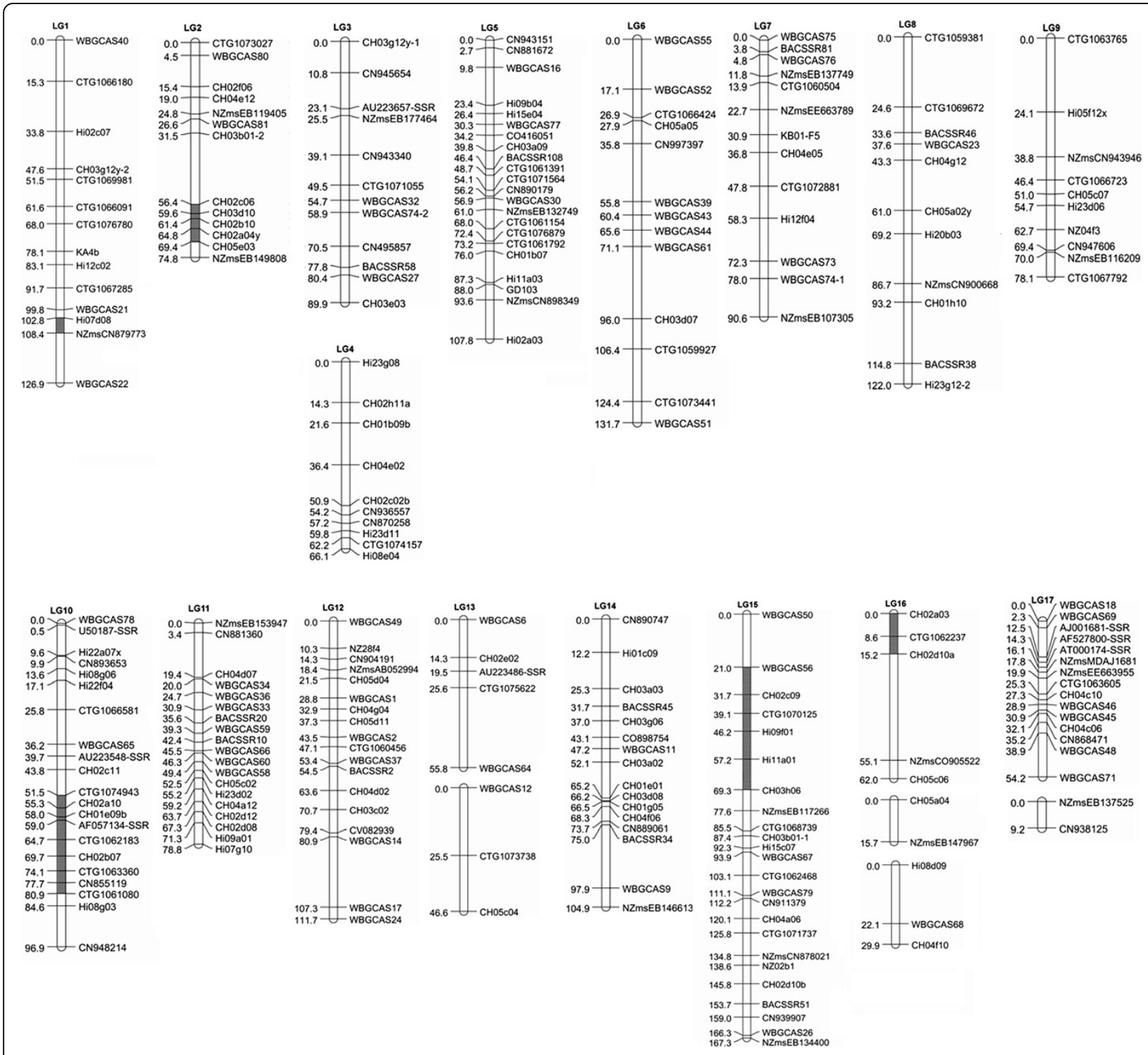

Figure 2 SSR-based genetic map of apple. M: male parent (cv. 'Golden Delicious'), F: female parent (cv. 'Jonathan'), and LG: linkage map. The consensus map is shown in centre, and distances shown in the maps are measured in centimorgans (cM). The number of linkage groups corresponds to the number of the haploid chromosomes of the draft apple genome sequence [8]. Segregation-distorted markers clustered within the chromosomal region are indicated in gray.

that the total amount of repetitive elements in apple is estimated to be $352.6 \mathrm{Mb}$ in size, representing 47.5\% of the whole genome sequence [8]. Whereas, repetitive elements in Arabidopsis, cucumber, and rice account for $18.5 \%, 14.8 \%$, and $39.5 \%$ of their whole genome sequences, respectively [8]. It has been reported that microsatellites are preferentially associated with nonrepetitive DNA in plant genomes [25]. Thus, abundance of repetitive sequences in the apple genome may also contribute to the observed low frequency of SSRs.

More recently, Cavagnaro et al. [24] have analyzed microsatellites in different plants, and found that tri- nucleotide repeats are the most prevalent type of SSRs in Arabidopsis, soybean, rice, and sorghum, while tetranucleotide repeats are most prevalent in poplar and grapevine. In this study, di-nucleotide repeats are the most abundant SSRs in apple, accounting for $~ 71.9 \%$ of all SSRs. This clearly suggests that repeat units of the most abundant SSRs in different plants vary considerably in size. However, it is not known whether or not this variation is related to plant speciation. Moreover, most SSRs identified in apple are less than 30 bp in length, and very few SSRs are longer than $50 \mathrm{bp}$. The observed distribution of lengths of SSRs in this study is consistent 
with previous findings that the frequency of repeat types decreases exponentially with repeat lengths [26].

In apple, SSRs are strongly biased towards AT-rich repeat motifs. For example, AT/TA repeats are not only the predominant dimers, but they are also the most frequent motifs in the entire genome. Moreover, only a single $\mathrm{GC}$ repeat with at least $20 \mathrm{bp}$ in length is present in the apple genome. Similarly, among all tri-, tetra-, penta, and hexa-nucleotide repeats found in the apple genome, AT-rich repeats are the most abundant SSRs. However, GC-rich motifs are quite few, and only 7, 2, and 9 of GGC/CCG/GCG/CGC, GCCG/GGGC, and CCCCG/ GCCCG/GCGGG repeats, respectively, are detected in the apple genome. These results are in agreement with previous findings that AT-rich SSRs are predominant in such dicots as Arabidopsis [27], papaya [28], soybean [29], and cucumber [24]; while GC-rich repeats are predominant in monocots, and most are present in coding regions [30]. It has been reported that GC contents in monocots are generally higher than those found in dicots [24]. Thus, the basal composition of the genome may play an important role in determining the types of observed SSRs in higher plants.

The predominance of tri- and hexa-nucleotide repeats in coding DNA sequences has been widely reported in several plant species $[23,24,31]$. In this study, tri- and hexa-nucleotide repeats prevail in coding DNA sequences of apple, accounting for $51.7 \%$ and $28.5 \%$ of all CDS-SSRs, respectively. The abundance of tri- and hexa-nucleotide repeats in plants may be attributed to negative selection against frame-shift mutations. Moreover, CCG/CGC/GCC repeats prevail in coding DNA sequences of rice [23]; while AGG/GAG/GGA repeats are the most abundant in coding DNA sequences of apple. Thus, positive selection for specific single aminoacid stretches may be involved in expansion of trinucleotide repeats in plants [25].

In this study, gSSRs detected more alleles and higher PIC values than either CDS-SSRs or UTR-SSRs. This is consistent with previous findings that suggested that EST-SSRs have lower levels of allele variations than gSSRs [22]. Di-nucleotide repeats prevail in apple, and the most frequent motifs in genomic and transcribed regions are AT/TA and AG/GA, respectively. Of dimeric gSSRs, AG/GA motifs have revealed more alleles and higher PIC values than AT/TA or AC/CA motifs. AG/ GA repeats in transcribed sequences have detected higher PIC values in eight apple genotypes than in other dimeric EST-SSRs. In a previous study, 825 EST-SSRs used to evaluate polymorphisms in two apple genotypes, 'Co-op 16' and 'Co-op 17', have shown that 28.8\%, 22.1\%, and $15.8 \%$ of AG/GA, AT/TA, and AC/CA repeats are polymorphic, respectively [18]. Therefore, it seems that AG/GA repeats in either genomic or transcribed regions may be more variable when compared with their counterparts of AT/TA and AC/CA repeats in apple. The AG/GA repeats may be more efficient than any other types of SSRs for genetic diversity studies and for linkage map construction in apple. In addition, SSRs have detected more alleles and higher PIC values in the four apple cultivars than in the four wild apple species. This suggests that SSR motifs in apple are less variable in cultivars than in wild species, which may be attributed to domestication of the apple.

\section{Transferability and segregation distortion of apple SSRs among populations}

Recently, a total of 312 EST-SSRs were mapped onto an apple linkage map using the mapping population 'Co-op $17^{\prime} \times$ 'Co-op16' [18]. In this study, these EST-SSRs were selected to construct a genetic linkage map, and 64 (20.5\%) were found to be polymorphic between 'Jonathan' and 'Golden Delicious'. Moreover, of 296 previously reported gSSRs, prefixed with ' $\mathrm{CH}$ ' or ' $\mathrm{Hi}$ ' $[17,32,33]$, used to screen the two parents 'Jonathan' and 'Golden Delicious', 94 (31.8\%) gSSRs were found to be polymorphic between these two parents and 90 (30.4\%) gSSRs were successfully anchored onto the genetic linkage map. Similarly, of 254 previously published gSSRs, prefixed with 'CH' or ' $\mathrm{Hi}$ ' $[17,32,33]$, used to construct a linkage map for 'Co-op 17' × 'Co-op16', 81 (31.9\%) displayed polymorphisms between 'Co-op 17' and 'Co-op 16' [18]. This indicated that the level of transferability of apple SSRs was not high among populations, and gSSRs exhibited higher levels of polymorphism than EST-SSRs ( 32\% versus $\sim 21 \%)$.

The above findings may be attributed to the fact that DNA sequences are known to be conserved in expressed regions. Moreover, among 310 gSSRs identified from the assembled genome sequence of apple selected to amplify both apple cultivars and wild species, $48.3 \%$ are found to be polymorphic among cultivars and wild species; whereas, only $21.6 \%$ are polymorphic between 'Jonathan' and 'Golden Delicious'. Therefore, using the mapping population from a cross between a domesticated cultivar and a wild species would aid in constructing an SSRbased genetic linkage map for apple.

In addition to low levels of transferability observed in this study, a high frequency of segregation distortion (20.7\%) was also observed among apple SSRs. Segregation distortions have been reported in other apple mapping populations, and up to $27.5 \%$ of markers have shown segregation distortion in a cross between 'Wijcik McIntosh' and 'NY75441-58' [12,16,32,34]. A high frequency of segregation distortion (20.3\%) has also been noted for SSRs in grapevine [35]. Segregation distortion is generally reported to be due to presence of lethal genes influencing viability of gametes and/or zygotes 
[36]. Therefore, a cluster of markers within the chromosomal region surrounding lethal genes will always show segregation distortion [37]. In apple, clustering of markers with distorted segregation has been previously observed for linkage group 10 [12,32,34]. In this study, $5,9,6$, and 3 SSRs with distorted segregations are clustered within a region on consensus linkage groups 2 (56.4 - 69.4 cM), 10 (51.5 - $80.9 \mathrm{cM}), 15$ (21.0 - 69.3 $\mathrm{cM})$, and $16(0.0-15.2 \mathrm{cM})$, respectively (Figure 2$)$. These segregation distortion regions may contain genes influencing viability of gametes and/or zygotes [32]. Moreover, two SSRs, Hi07d08 and NZmsCN879773, with distorted segregation are also found to be clustered on linkage group 1 (Figure 2). When comparing linkage group 1 in this study with previously reported genetic linkage maps, it is found that these two SSRs are linked to $V f$ genes for scab resistance in apple $[18,38]$. It has been reported that $V f$ genes in apple are linked to sublethal genes [39]. Thus, such lethal genes are likely to be responsible for the observed distorted segregation of the two clustered SSRs Hi07d08 and NZmsCN879773. In addition, SSRs with distorted segregation across the same linkage group are also observed in this study. For example, three SSRs, including CTG1066180, ctg1076780, and Hi12c02 show distorted segregation, and are located in different regions of linkage group 1 . Thus, it seems that other factors such as chromosome loss and selfincompatibility may be also involved in segregation distortion in apple [40,41].

\section{Utilization of SSR motifs identified from assembled genome sequences of apple}

Initially, almost all published SSRs were used to construct the genetic linkage map for apple using $F_{1}$ seedlings from the cross between 'Jonathan' and 'Golden Delicious'. However, only $\sim 200$ SSRs were found to be polymorphic between these two parents. To aid in subsequent linkage map construction, developing additional SSR markers was deemed necessary. Therefore, SSR motifs in assembled genome sequences of apple were analyzed, and more than 300 SSRs across the whole genome were selected to screen the two parents of the mapping population used in this study. As a result, 81 additional gSSRs were developed, and an SSR-based linkage map of apple was successfully developed. These results demonstrated that exploring and using SSRs from the draft of the apple genome sequence were efficient for constructing a genetic linkage map. As more than 28,000 SSR motifs were present in the apple genome, this allowed for developing an SSR-based highdensity linkage map using a high-throughput genotyping technology such as the fluorescent capillary electrophoresis [18].
In this study, a total of 54 gSSRs, identified from the apple genome sequence, were genetically mapped onto 15 linkage groups. Mapping results of these gSSRs were compared with their positions along the draft of the apple genome sequence [8]. Surprisingly, 13 out of 54 gSSRs revealed inconsistencies between their geneticmap positions and sequence-based physical-map positions (Additional file 4). Similarly, when comparing DNA sequences flanking SSRs against the apple genome sequence, 23 previously developed SSRs showed discrepancies between their genetic-map and sequence-based physical-map positions (Additional file 4). Moreover, primer sequences of 36 discrepant SSRs were also compared against the apple genome sequence, and results indicated that all these SSRs were likely to be single loci. Additionally, genetic-map positions of 196 previously developed SSRs on the consensus linkage map were compared with earlier results. Of 196 SSRs, 192 were mapped onto the same linkage groups as previously reported $[17,18,21,32,33]$. Two SSRs, CH01b09b and CH04g12, were for the first time genetically mapped onto linkage groups 4 and 8 , respectively. Previously, the two gSSRs CH03b01 and Hi08g03 were mapped onto linkage groups 2 and 6, respectively [15,17]; however, in this study, CH03b01 was mapped onto two linkage groups 2 and 15, while Hi08g03 was mapped onto linkage group 10. CH03b01 and Hi08g03 have been reported to be multi-locus SSRs [15,17], and linkage group 2 was homologous to linkage group $15[8,18]$. Thus, the genetic mapping results of $\mathrm{CH} 03 \mathrm{~b} 01$ and $\mathrm{HiO} 0 \mathrm{~g} 03$ observed in this study are likely to be accurate.

Overall, the genetic positions of published SSRs in this genetic linkage map are consistent with previous reports, thus suggesting that mapping results of SSRs from the draft sequence of the apple genome are reliable. However, it seems that a small portion of assembled contig sequences of the apple genome may not be correctly anchored onto apple chromosomes. Of 36 discrepant SSRs, nine are located on linkage group 10 (Additional file 4), indicating that the draft sequence of chromosome 10 may be less reliable when compared with those of other chromosomes.

\section{QTLs for fruit acidity}

Acidity plays an important role in determining fruit quality, and several studies have been carried out to identify QTLs responsible for fruit acidity in both apple and peach $[12,16,32,42]$. In apple, a major QTL or $M a$ gene, responsible for fruit acidity, has been mapped onto linkage group 16, and this can explain $\sim 30 \%$ of the observed variance [32,43]. In addition to the $M a$ gene, six other QTLs for apple fruit acidity have also been detected on linkage groups $2,8,10,13,15$, and 17 $[32,43]$. In this study, the newly developed linkage map 
of apple has been used to identify QTLs for fruit acidity. As malic acid is the major acid in apples [44], malic acid content instead of fruit $\mathrm{pH}$ or titratable acidity has been used to characterize apple fruit acidity in this study. A QTL responsible for malic acid content of apple fruits is detected on linkage group 8 of $\mathrm{cv}$. 'Jonathan'. This QTL is linked to SSR marker $\mathrm{CH} 05 \mathrm{a} 02 \mathrm{y}$, and this is consistent with the finding reported by Liebhard et al. [45]. Thus, it seems that the QTL for apple fruit acidity detected in this study is reliable, although the QTL analysis has been performed using phenotyping data from a single year (2009), as most seedlings have not fruited either due to incidence of damaging cold temperatures during flowering or outbreak of canker disease. It is worth noting that the effect of QTLs for apple fruit acidity may have been underestimated due to low marker density of linkage map groups and the small mapping population size. Additionally, some linkage groups are split into two with gaps of unknown lengths. The large gaps in some linkage groups, together with low marker density as well as the small population size may all have contributed to inability in detecting some QTLs with small effects. In this study, a QTL with a peak LOD value of 2.2 is detected on linkage group 5, but this QTL is not recorded as its LOD value is lower than the cutoff threshold value of 2.8 .

\section{Conclusions}

This study provides insights into the characteristics of microsatellites in apple. Overall the apple genome, dinucleotide repeats are the most frequent SSRs, accounting for $71.9 \%$ of all SSRs. A key new finding is that among these di-nucleotide repeats, AT/TA and AG/GA are the most frequent in genomic and transcribed regions of apple, respectively. AG/GA repeats are more variable than AT/TA or AC/CA repeats in apple. A total of 310 primer pairs of SSRs have been designed to assess their polymorphisms, and $245(79.0 \%)$ are found to be polymorphic in eight apple genotypes. The newly developed SSRs in this study, together with previously published SSRs, have been used to construct a genetic linkage map for apple using an $F_{1}$ population derived from a cross between 'Jonathan' and 'Golden Delicious'. The genetic mapping results indicate that gSSRs have higher levels of polymorphism among different mapping populations of apple than EST-SSRs. Distortionsegregated markers have been clustered along several chromosome regions. A QTL responsible for malic acid content of apple fruits has been detected on linkage group 8 of apple cv. 'Jonathan'.

Briefly, the apple genome is rich in di-nucleotide repeats, and AG/GA repeats are more variable than other dimers. The availability of a very large set of microsatellite markers distributed throughout the genome may facilitate a variety of genomic studies in apple, including development of high-resolution linkage maps, positional genecloning, and fine-mapping of QTLs/genes.

\section{Methods}

\section{Plant material}

A segregating $F_{1}$ population derived from a cross between 'Jonathan' and 'Golden Delicious', maintained at the Changli Institute of Pomology (Hebei Province, PRC), was used for linkage map construction. The segregating population consisted of 286 individual seedlings. Young leaves of these apple seedlings and their parents were collected for DNA isolation.

\section{Identification of SSRs}

The assembled sequence of the 'Golden Delicious' apple genome was downloaded from the Genome Database for Rosaceae (http://www.rosaceae.org/projects/ apple_genome). Assembly sequences of the apple genome were scanned for perfect microsatellites (uninterrupted run of repeats) using the computer program MIcroSAtellite identification tool (MISA). SSRs recorded for the final dataset included dimers to hexamers of at least $20 \mathrm{bp}$ in length.

\section{Analysis of SSR genotyping}

Primers were designed based on flanking sequences of SSRs using the Primer 3 program (http://primer3.sour ceforge.net/). Amplification was performed under the following conditions: $3 \mathrm{~min}$ at $95^{\circ} \mathrm{C}$, followed by 35 cycles of $45 \mathrm{~s}$ at $94^{\circ} \mathrm{C}, 45 \mathrm{~s}$ at $55^{\circ} \mathrm{C}, 45 \mathrm{~s}$ at $72^{\circ} \mathrm{C}$, and a final extension step at $72^{\circ} \mathrm{C}$ for $10 \mathrm{~min}$. Five $\mu \mathrm{L}$ of amplification products was mixed with an equal volume of formamide loading buffer ( $98 \%$ formamide, $10 \mathrm{mM}$ EDTA, pH 8.0, 0.025\% bromophenol blue and xylene cyanol). The mixture was denatured at $94^{\circ} \mathrm{C}$ for $3 \mathrm{~min}$, and then immediately chilled on ice. An aliquot of $2 \mu \mathrm{L}$ mixture was loaded on a $6 \%$ polyacrylamide gel, and electrophoresed for $1.5 \mathrm{~h}$ at $1200 \mathrm{~V}$. Bands were visualized after silver staining, and recorded on a ScanMaker 3830 (Microtek, Shanghai, China).

\section{Investigation of polymorphism of SSRs in apple cultivars and wild species}

Evaluation of SSR polymorphism was conducted using four apple cultivars, including 'Golden Delicious', 'Jonathan', 'Luao,' and 'Starkrimson', along with four wild apple species, including M. prunifolia (Willd.) Borkh. ('Regunzihaitang'), M. sieversii (Lebed.) Roem. ('Xinjiangyepingguo 12'), M. × robusta Rehd. ('Pingding Crab'), and M. asiatica Nakai ('Naizi'). SSRs exhibiting polymorphisms among the eight apple genotypes were subjected to calculated polymorphism 
information content (PIC) values following the protocol described by Zhang et al. [46] .

\section{Construction of a genetic linkage map and QTL analysis} A total of $286 \mathrm{~F}_{1}$ seedlings derived from a cross between 'Jonathan' and 'Golden Delicious' were used for the construction of genetic linkage maps for apple. The linkage analysis was carried out using JoinMap version 4.0 [47], as previously described by Han et al. [18]. Briefly, an LOD score threshold of 8.0 was initially used to assign markers to different linkage groups. Once linkage groups were determined, the remaining markers were added to their corresponding groups using a less stringent criterion of LOD score of 4.0. Genetic maps for each parent were constructed using the function of 'Create Maternal and Paternal Node' in the JoinMap program. The regression mapping algorithm was used for map construction. Map distances were calculated using Kosambi's mapping function, and denoted in centiMorgans (cM). Once the genetic maps for each parent were constructed, a consensus map was built using the $\mathrm{CP}$ population model. Order of markers in genetic maps for each parent was used as preferred orders (the 'fixed order' function) for the construction of a consensus map.

QTL analysis was conducted using MapQTL v4 [48]. Genetic linkage maps for each parent were used to detect QTLs using an interval mapping approach, and an LOD score of 2.8 was set as a genome-wide threshold to declare significant QTLs.

\section{Analysis of malic acid content in apple fruits}

Three apple fruits from each progeny were collected at maturity, cut into small sections, and then stored at $-70^{\circ} \mathrm{C}$ until use. One gram of fresh fruit was ground into a fine power in liquid nitrogen, and dissolved in $10 \mathrm{~mL}$ of $80 \%$ methanol ( $\mathrm{pH} 7,0.1 \mathrm{M}$ imidazole). The mixture was incubated for $15 \mathrm{~min}$ at $75^{\circ} \mathrm{C}$, sonicated for $20 \mathrm{~min}$ in an ultrasonic water bath, and centrifuged at $10,000 \mathrm{~g}$ for $10 \mathrm{~min}$ at room temperature. A total of $980 \mu \mathrm{L}$ of the supernatant and $20 \mu \mathrm{L}$ of an inner standard $(2.5 \%$ methl- $\alpha$-D- glucopyranoside, $2.5 \%$ phenyl- $\beta$-D-glucopyranoside, and $10 \%$ acetone) were mixed, and then centrifuged at $10,000 \mathrm{~g}$ for $20 \mathrm{~min}$ at room temperature. An aliquot of $0.5 \mathrm{~mL}$ from each sample was evaporated to dryness, and the residue was dissolved in $0.8 \mathrm{~mL}$ of hydroxylamine hydrochloride solution in pyridine $(20 \mathrm{mg} / \mathrm{ml})$. The mixture was incubated at $75^{\circ} \mathrm{C}$ for $1 \mathrm{~h}$, and then cooled down to room temperature. Subsequently, $0.4 \mathrm{~mL}$ of hexamethyldisilazane and $0.2 \mathrm{~mL}$ of trimethylchlorosilane were added. Following incubation at $75^{\circ} \mathrm{C}$ for $2 \mathrm{~h}$, the mixture was centrifuged at $12,000 \mathrm{~g}$ for $20 \mathrm{~min}$ at room temperature. A total of $0.5 \mathrm{~mL}$ of supernatant was subjected to gas chromatography analysis (Agilnet 6890N, USA) to estimate the concentration of organic acid content as described by Morvai and Molnár-Per [49].

\section{Additional files}

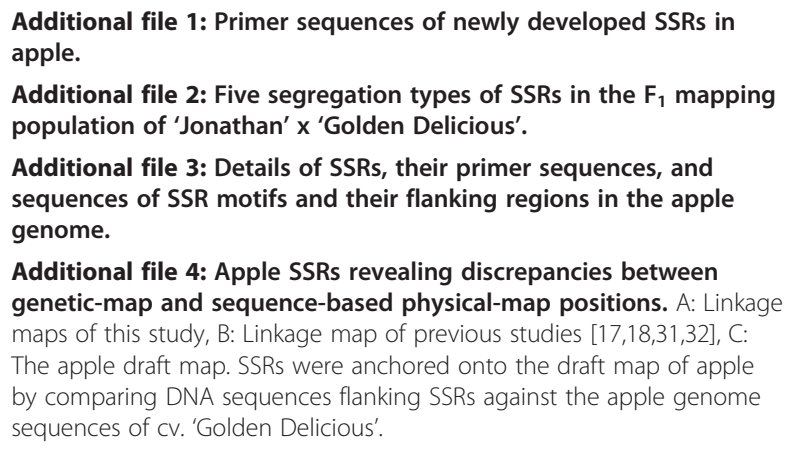

Additional file 4: Apple SSRs revealing discrepancies between genetic-map and sequence-based physical-map positions. A: Linkage maps of this study, B: Linkage map of previous studies [17,18,31,32], C: The apple draft map. SSRs were anchored onto the draft map of apple by comparing DNA sequences flanking SSRs against the apple genome sequences of cv. 'Golden Delicious'.

\section{Competing interests}

The authors declare that there are no competing interests.

\section{Authors' contributions}

$\mathrm{QZ}, \mathrm{BM}, \mathrm{HL}, \mathrm{YC}$, and YYH participated in SSR genotyping and linkage analysis. MAK, SSK, and SL participated in QTL mapping and manuscript preparation. $X Z$ and $Z$ H developed the segregating populations. JL, SZ and GW collected phenotype data. YPH was overall project leader. All authors read and approved the final manuscript.

\section{Acknowledgements}

We would like to thank Dr. Han Zhao for his bioinformatics analysis. This project was supported by funds received from National Program on Key Basic Research Project of China (973 Program) under grant

No.2011CB100600, the National Science Foundation of China under Grant No. 30971987, and the National 863 program of China (No. 2011AA0020401). This project was also partially supported by the Chinese Academy of Sciences Visiting Professorship for Senior International Scientists (No. 2011T2S25).

\section{Author details}

${ }^{1}$ Key Laboratory of Plant Germplasm Enhancement and Specialty Agriculture, Wuhan Botanical Garden, the Chinese Academy of Sciences, Wuhan 430074, People's Republic of China. ${ }^{2}$ Graduate School of the Chinese Academy of Science, Beijing 100039, People's Republic of China. ${ }^{3}$ Institute for Horticultural Plants, China Agricultural University, Beijing 100193, People's Republic of China. ${ }^{4}$ Department of Natural Resources and Environmental Sciences, University of Illinois, 1201 W. Gregory, Urbana, IL 61801, USA.

Received: 25 May 2012 Accepted: 4 October 2012

Published: 7 October 2012

\section{References}

1. Khan MA, Duffy B, Gessler C, Patocchi A: QTL mapping of fire blight resistance in apple. Mol Breed 2006, 17:299-306.

2. Khan MA, Duffy B, Durel CE, Denancé C, Kellerhals M, Patocchi A, Gessler C: Development of markers linked to the 'Fiesta' 7 major QTL for fire blight resistance and their application for marker-assisted selection. Genome 2007, 50:568-577.

3. Bus VGM, Chagné D, Bassett HCM, Bowatte D, Calenge F, Celton J-M, Durel CE, Malone MT, Patocchi A, Ranatunga AC, Rikkerink EHA, Tustin DS, Zhou J, Gardiner SE: Genome mapping of three major resistance genes to woolly apple aphid (Eriosoma lanigerum Hausm.). Tree Genet Genomes 2008, 4:233-236.

4. Le Roux PM, Khan MA, Broggini GA, Duffy B, Gessler C, Patocchi A: Mapping of quantitative trait loci for fire blight resistance in the apple cultivars 'Florina' and 'Nova Easygro'. Genome 2010, 53:710-722. 
5. Kenis K, Keulemans J: Study of tree architecture of apple (Malus x domestica Borkh.) by QTL analysis of growth traits. Mol Breed 2007, 19:193-208.

6. Segura V, Durel C, Costes E: Dissecting apple tree architecture into genetic, ontogenetic and environmental effects: QTL mapping. Tree Genet Genomes 2009, 5:165-179.

7. Katrien K, Johan K, Mark WD: Identification and stability of QTLs for fruit quality traits in apple. Tree Genet Genomes 2008, 4:647-661.

8. Velasco R, Zharkikh A, Affourtit J, Dhingra A, Cestaro A, Kalyanaraman A, Fontana P, Bhatnagar SK, Troggio M, Pruss D, Salvi S, Pindo M, Baldi P, Castelletti S, Cavaiuolo M, Coppola G, Costa F, Cova V, Dal Ri A, Goremykin V, Komjanc M, Longhi S, Magnago P, Malacarne G, Malnoy M, Micheletti D, Moretto M, Perazzolli M, Si-Ammour A, Vezzulli S, Zini E, Eldredge G, Fitzgerald LM, Gutin N, Lanchbury J, Macalma T, Mitchell JT, Reid J, Wardell B, Kodira C, Chen Z, Desany B, Niazi F, Palmer M, Koepke T, Jiwan D, Schaeffer S, Krishnan V, Wu C, Chu VT, King ST, Vick J, Tao Q, Mraz A, Stormo A, Stormo K, Bogden R, Ederle D, Stella A, Vecchietti A, Kater MM, Masiero S, Lasserre P, Lespinasse Y, Allan AC, Bus V, Chagné D, Crowhurst RN, Gleave AP, Lavezzo E, Fawcett JA, Proost S, Rouzé P, Sterck L, Toppo S, Lazzari B, Hellens RP, Durel CE, Gutin A, Bumgarner RE, Gardiner SE, Skolnick M, Egholm M, Van de Peer Y, Salamini F, Viola R: The genome of the domesticated apple (Malus $\mathrm{x}$ domestica Borkh.). Nat Genet 2010, 42:833-839.

9. Newcomb RD, Crowhurst RN, Gleave AP, Rikkerink EH, Allan AC, Beuning LL, Bowen JH, Gera E, Jamieson KR, Janssen BJ, Laing WA, McArtney S, Nain B, Ross GS, Snowden KC, Souleyre EJ, Walton EF, Yauk YK: Analysis of expressed sequence tags from apple. Plant Physiol 2006, 141:147-166.

10. Gasic K, Gonzalez DO, Thimmapuram J, Liu L, Malnoy M, Gong G, Han Y, Vodkin LO, Aldwinckle HS, Carroll NJ, Orvis KS, Goldsbrough P, Clifton S, Pape D, Fulton L, Martin J, Theising B, Wisniewski ME, Fazio G, Feltus FA, Korban SS: Comparative analysis and functional annotation of a large expressed sequence tag collection of apple. Plant Genome 2009, 2:23-38.

11. Han Y, Gasic K, Marron B, Beever JE, Korban SS: A BAC-based physical map of the apple genome. Genomics 2007, 89:630-637.

12. Maliepaard C, Alston FH, van Arkel G, Brown LM, Chevreau E, Dunemann F, Evans KM, Gardiner S, Guilford P, van Heusden AW, Janse J, Laurens F, Lynn JR, Manganaris AG, den Nijs APM, Periam N, Rikkerink E, Roche P, Ryder C, Sansavini S, Schmidt H, Tartarini S, Verhaegh JJ, Vrielink-van Ginkel M, King $\mathrm{CJ}$ : Aligning male and female linkage maps of apple (Malus pumila Mill.) using multi-allelic markers. Theor Appl Genet 1998, 97:60-73.

13. Guilford P, Prakash S, Zhu J, Rikkerink E, Gardiner S, Basset H, Forster R: Microsatellites in Malus $\mathrm{x}$ domestica (apple): abundance, polymorphism and cultivar identification. Theor App/ Genet 1997, 94:249-254.

14. Gianfranceschi L, Seglias N, Tarchini R, Komjanc M, Gessler C: Simple sequence repeats for the genetic analysis of apple. Theor Appl Genet 1998, 96:1069-1076.

15. Liebhard R, Gianfranceschi L, Koller B, Ryder CD, Tarchini R, Van de Weg E, Gessler C: Development and characterisation of 140 new microsatellites in apple (Malus x domestica Borkh.). Mol Breed 2002, 10:217-241.

16. Kenis K, Keulemans J: Genetic linkage maps of two apple cultivars (Malus $\mathrm{x}$ domestica Borkh.) based on AFLP and microsatellite markers. Mol Breed 2005, 15:205-219.

17. Silfverberg-Dilworth E, Matasci CL, Van de Weg WE, Van Kaauwen MPW, Walser M, Kodde LP, Soglio V, Gianfranceschi L, Durel CE, Costa F, Yamamoto T, Koller B, Gessler C, Patocchi A: Microsatellite markers spanning the apple (Malus $\mathrm{x}$ domestica Borkh.) genome. Tree Genet Genomes 2006, 2:202-224.

18. Han Y, Zheng D, Vimolmangkang S, Khan MA, Beever JE, Korban SS: Integration of physical and genetic maps in apple confirms wholegenome and segmental duplications in the apple genome. J Exp Bot 2011, 62:5117-5130.

19. Dirlewanger E, Graziano E, Joobeur T, Garriga-Calderé F, Cosson P, Howad W. Arús P: Comparative mapping and marker-assisted selection in Rosaceae fruit crops. Proc Natl Acad Sci USA 2004, 101:9891-9896.

20. Cuadrado A, Cardoso M, Jouve N: Physical organization of simple sequence repeats (SSRs) in Triticeae: structural, functional and evolutionary implications. Cytogenet Genome Res 2008, 120:210-219.

21. Celton JM, Tustin DS, Chagné D, Gardiner SE: Construction of a dense genetic linkage map for apple rootstocks using SSRs developed from Malus ESTs and Pyrus genomic sequences. Tree Genet Genomes 2009, 5:93-107.

22. Ellegren $\mathrm{H}$ : Microsatellites: simple sequences with complex evolution. Nat Rev Genet 2004, 5:435-445.
23. Lawson MJ, Zhang L: Distinct patterns of SSR distribution in the Arabidopsis thaliana and rice genomes. Genome Biol 2006, 7:R14

24. Cavagnaro PF, Senalik DA, Yang L, Simon PW, Harkins TT, Kodira CD, Huang $S$, Weng Y: Genome-wide characterization of simple sequence repeats in cucumber (Cucumis sativus L.). BMC Genomics 2010, 11:569.

25. Morgante $M$, Hanafey $M$, Powell W: Microsatellites are preferentially associated with nonrepetitive DNA in plant genomes. Nat Genet 2002, 30:194-200.

26. Katti MV, Ranjekar PK, Gupta VS: Differential distribution of simple sequence repeats in eukaryotic genome sequences. Mol Biol Evol 2001, 18:1161-1167.

27. Tamanna A, Khan AU: Mapping and analysis of simple sequence repeats in the Arabidopsis thaliana genome. Bioinformation 2005, 1:64-68.

28. Lai CWJ, Yu Q, Hou S, Skelton RL, Jones MR, Lewis KLT, Murray J, Eustice M, Guan P, Agbayani R, Moore PH, Ming R, Presting GG: Analysis of papaya $B A C$ end sequences reveals first insights into the organization of a fruit tree genome. Mol Genet Genomics 2006, 276:1617-4615.

29. Shultz JL, Kazi S, Bashir R, Afzal JA, Lightfoot DA: The development of BAC-end sequence-based microsatellite markers and placement in the physical and genetic maps of soybean. Theor Appl Genet 2007, 114:1081-1090.

30. Sonah H, Deshmukh RK, Sharma A, Singh VP, Gupta DK, Gacche RN, Rana JC, Singh NK, Sharma TR: Genome-wide distribution and organization of microsatellites in plants: an insight into marker development in Brachypodium. PLoS One 2011, 6:e21298.

31. Mun JH, Kim DJ, Choi HK, Gish J, Debellé F, Mudge J, Denny R, Endré G, Saurat O, Dudez AM, Kiss GB, Roe B, Young ND, Cook DR: Distribution of microsatellites in the genome of Medicago truncatula: a resource of genetic markers that integrate genetic and physical maps. Genetics 2006, 172:2541-2555.

32. Liebhard R, Koller B, Gianfranceschi L, Gessler C: Creating a saturated reference map for the apple (Malus $\times$ domestica Borkh.) genome. Theor Appl Genet 2003, 106:1497-1508.

33. N'Diaye A, Van de Weg WE, Kodde LP, Koller B, Dunemann F, Thiermann M, Tartarini S, Gennari F, Durel CE: Construction of an integrated consensus map of the apple genome based on four mapping populations. Tree Genet Genomes 2008, 4:727-743.

34. Conner PJ, Brown SK, Weeden NF: Randomly amplified polymorhic DNAbased genetic linkage maps of three apple cultivars. J Am Soc Hortic Sci 1997, 122:350-359.

35. Troggio M, Malacarne G, Coppola G, Segala C, Cartwright DA, Pindo M, Stefanini M, Mank R, Moroldo M, Morgante M, Grando MS, Velasco R: A dense single-nucleotide polymorphism-based genetic linkage map of grapevine (Vitis vinifera L.) anchoring Pinot Noir bacterial artificial chromosome contigs. Genetics 2007, 176:2637-2650.

36. Cervera MT, Storme V, Ivens B, Gusmão J, Liu B, Hostyn V, Van Slycken M, Van Montague M, Boerjan W: Dense genetic linkage maps of three Populus species (Populus deltoides, P. nigra and P. trichocarpa) based on AFLP and microsatellite markers. Genetics 2001, 158:787-809.

37. Vogl C, Xu S: Multipoint mapping of viability and segregation distorting loci using molecular markers. Genetics 2000, 155:1439-1447.

38. Vinatzer BA, Patocchi A, Tartarini S, Gianfranceschi L, Sansavini S, Gessler C: Isolation of two microsatellite markers from BAC clones of the Vf scab resistance. Plant Breed 2004, 123:321-326.

39. Gao Z, Van De Weg WE: The Vf gene for scab resistance in apple is linked to sub-lethal genes. Euphytica 2006, 151:123-132.

40. Kasha KJ, Kao KN: High frequency haploid production in barley (Hordeum vulgare L.). Nature 1970, 225:874-876

41. Savolainen $\mathrm{O}$, Kärkkäinen $\mathrm{K}$, Kuittinen $\mathrm{H}$ : Estimating numbers of embryonic lethals in conifers. Heredity 1992, 69:308-314.

42. Boudehri K, Bendahmane A, Cardinet G, Troadec C, Moing A, Dirlewanger E: Phenotypic and fine genetic characterization of the $D$ locus controlling fruit acidity in peach. BMC Plant Biol 2009, 9:59.

43. Kenis K, Keulemans J, Davey M: Identification and stability of QTLs for fruit quality traits in apple. Tree Genet Genomes 2008, 4:647-661.

44. Zhang Y, Li P, Cheng L: Developmental changes of carbohydrates, organic acids, amino acids, and phenolic compounds in 'Honeycrisp' apple flesh. Food Chem 2010, 123:1013-1018.

45. Liebhard R, Kellerhals M, Pfammatter W, Jertmini M, Gessler C: Mapping quantitative physiological traits in apple (Malus $\mathrm{x}$ domestica Borkh.). Plant Mol Biol 2003, 52:511-526.

46. Zhang Q, Li J, Zhao Y, Korban SS, Han Y: Evaluation of genetic diversity in Chinese wild apple species along with apple cultivars using SSR markers. Plant Mol Biol Rep 2012, 30:539-546. 
47. Van Ooijen JW: JoinMap ${ }^{\circledR}$ 4, Software for the calculation of genetic linkage maps in experimental populations. Wageningen, Netherlands: Kyazma B.V 2006.

48. Van Ooijen JW, Boer MP, Jansen RC, Maliepaard C: MapQTL 4.0; Software for the calculation of QTL positions on genetic maps. Wageningen: Plant Research International B.V; 2002.

49. Morvai M, Molnár-Per I: Simultaneous gas chromatographic quantitation of sugars and acids in citrus fruits, pears, bananas, grapes, apples and tomatoes. Chromatogr 1992, 34:502-504.

doi:10.1186/1471-2164-13-537

Cite this article as: Zhang et al: Identification, characterization, and utilization of genome-wide simple sequence repeats to identify a QTL for acidity in apple. BMC Genomics 2012 13:537.

\section{Submit your next manuscript to BioMed Central and take full advantage of:}

- Convenient online submission

- Thorough peer review

- No space constraints or color figure charges

- Immediate publication on acceptance

- Inclusion in PubMed, CAS, Scopus and Google Scholar

- Research which is freely available for redistribution 